\title{
The Capstone Sales Course: An Integral Part of a University Level Professional Selling Program
}

\author{
David Titus ${ }^{1}$, Garth Harris ${ }^{1}$, Rajesh Gulati ${ }^{1} \&$ Dennis Bristow ${ }^{1}$ \\ ${ }^{1}$ Herberger Business School, St. Cloud State University, St. Cloud, MN, USA \\ Correspondence: Dennis Bristow, Herberger Business School, St. Cloud State University, St. Cloud, MN USA. Tel: \\ $1-320-308-5125$
}

Received: April 17, 2017

Accepted: June 26, 2017

Online Published: July 15, 2017

doi:10.5430/ijhe.v6n4p28

URL: https://doi.org/10.5430/ijhe.v6n4p28

\begin{abstract}
The Capstone Sales course is the final in a sequence of five required courses in a 15 credit Professional Selling program housed in the Marketing Department at St. Cloud State University. The course is heavily focused on experiential learning activities for senior-level sales students. In this paper details of the course design, instructor and student deliverables, grading rubrics, student project/assignment guidelines, and a suggested course schedule are presented.
\end{abstract}

Keywords: Marketing, Professional Selling, Sales Management, Higher Education

\section{Introduction}

The world of professional selling and sales management offers students and university professors alike myriad opportunities and challenges. For example, the professional selling discipline offers tremendous personal and career opportunities for well-prepared college and university graduates. On the firm's website, Humres Technical Recruitment (2017) proposes that "sales is one of the most enduring and versatile occupations on the planet, with a career in sales bringing you endless job options'. Selling Power Magazine (2016) reported that the top 200 sales firms in America will seek over half a million new salespeople. This same research showed that the top 30 direct-selling firms employed more salesforces totaling more than 24 million professionals. In 2013, Cummins, Peltier, Erffmeyer and Whalen reported predictions of continuing strong demand for professional salespeople.

And the world of professional selling is evolving in the wake of technology and changing consumer decision making. Canaday (2012) wrote that "social media has become the fastest-adapted new tool to hit professional B2B sales since...well maybe since time began." He also noted that salespeople use social media for a variety of uses, including collaboration with other reps and to work with customers. Agnihotri et. al., (2012) concluded that social media tools can be used by salespeople to build social networks and to develop knowledge bases. In their work published in 2015, Moore et. al. found that a 'substantially high' proportion of sales people, and an even higher proportion of sales managers, in both $\mathrm{B} 2 \mathrm{~B}$ and $\mathrm{B} 2 \mathrm{C}$ settings utilized social media for customer relationship management purposes. Featherstonebaugh (2010) reported that in a global survey of salespeople, nearly half of their buyers acknowledged an increase in the role of social media in buying process.

In university level sales education, the importance and effectiveness of experiential learning has been recognized and is being emphasized. Chapman, Schetzsle and Wahlers (2016) introduced an innovative experiential pedagogy for the teaching of sales management and professional selling skills. In their Marketing Education Review manuscript, Alavrez et. al., (2015) reported that a structured experiential simulation in a professional selling course improved students' critical thinking skills. Described as an innovative and highly flexible pedagogy used in sales courses, Hawes and Foley (2006) introduced Professional Activity Reports (emphasizing professional involvement, oral presentation, and written communication) and found them to be a key factor in enhancing the student learning experience.

This paper presents a detailed outline of a university level capstone professional selling course designed with the fundamental goals of providing senior-level sales students with a comparative advantage as they pursue professional selling careers, with knowledge and experience in utilizing social media selling tools in those careers. 


\section{Background}

In the Fall of 2014, the Marketing Department and the AACSB accredited Herberger Business School at St. Cloud State University (one of the largest public universities in the state of Minnesota, USA) added a new 15-credit certificate program, the "Professional Selling Specialization," to its curriculum. Subject to an electronic application and review process, this specialization can be pursued by any university student who has been accepted into his/her academic major. The program application includes the student's academic major(s), minor(s), overall GPA, major GPA, contact information, and a one page essay outlining the fitment of the sales program with his/her academic and career goals. All program applications are reviewed by a 4-member panel of sales faculty and, based upon student credentials, program objectives and student career goals, an accept/decline decision is reached for each applicant. Upon acceptance into the sales program, each student is assigned to a Professional Selling Specialization Academic Advisor who works with the student to develop a program completion plan. Students accepted into the program must complete a sequence of five specified 3-credit marketing and sales related courses (Introduction to Marketing; Marketing Communications; Professional Selling; Sales Management; Capstone Sales). The final course in that five course sequence, the Capstone Sales course, is designed to integrate the sales knowledge and skills students have acquired in the previous sales program courses and to build upon those skills via a pedagogy that combines experiential and classroom based learning activities. In the remainder of this manuscript, the authors present the rationale, architecture, content, and course implementation information regarding this course.

\section{The Course Description}

The overall learning outcome for the Capstone Sales course, which has been effectively taught in 50 minute, 75 minute and $31 \frac{1}{2}$ hour (once a week evening class) time blocks, is as follows:

At the end of this course, students will be better prepared for a career in professional sales and in sales management in the current environment.

The target market for the course consists of junior and senior level $\left(3^{\text {rd }}\right.$ and $4^{\text {th }}$ year $)$ university students. Prior to enrolling in the course, students must be accepted into the Professional Selling Specialization program via the application and review process outlined above and must have completed the first four courses in that program. The 3 -credit capstone course features four distinct modules (described in more detail below) and is taught by one primary instructor. The course was designed, however, with the option to assign additional instructors for one or more modules as and when appropriate. For example, when discussing international aspects of professional selling and sales management it might be effective to have that component of the course collaboratively taught by a faculty team consisting of the instructor of record and a faculty member specializing in global marketing.

In the coming paragraphs, the following components of the Capstone Sales class are detailed and discussed:

Course Module Description. This portion of the paper presents course content, suggested project(s), deliverables by students and instructor, and potential external resources involved in teaching the course. An overview of each of the four modules in the course - Social Media and Technology; Professional Selling Practicum and Shadowing; Sales Management Practicum and Shadowing; Global Marketing/Culture in Professional Selling -- is presented.

Instructor and Student Deliverables. Instructor expectations and student submissions are discussed.

Course Timelines and Activities. In this section of the manuscript, suggested course schedules, timelines and student assignments and activities for a 16 week semester-long course are presented (see Appendix A).

Grading Rubrics and Report Writing Guidelines. These course elements are discussed in the appropriate course modules and the specific documents are presented.

\section{Module 1: Social Media and Technology in Professional Selling (4 weeks)}

Content: With in-class information provided by the instructor and with further guidance from an assigned text or reading list (a suggested text is: "Maximizing LinkedIn for Sales and Social Media Marketing” by Neal Schaffer; the instructor can require a different textbook), students initiate a "LinkedIn Project" in the first week of this initial module of the course. This individual project is completed by the final class day of the $4^{\text {th }}$ week of the module. The course instructor has flexibility in deciding on the overall theme for the project (e.g., developing LinkedIn connections - connections with students interested in pursuing an undergraduate education, with representatives of firms interested in a new hire, with other professors, with colleagues on LinkedIn, with certain LinkedIn groups, etc.). An outline that includes some likely topics for this module is included below. Each instructor has the freedom to develop his/her own project that can be completed reasonably in 4 weeks. The instructor also has the option to allow additional time for project completion and submission if they so choose. The purpose of the project is to provide 
students with experiential learning opportunities in the building of a professional social media outlet, the goal of which is to find leads, to develop those leads, and to manage customer relationships.

During this module, students are also strongly encouraged to begin the process of identifying and initiating discussions with area sales people. This activity is detailed more fully in the discussion of Module 2 of the course.

Suggested Module 1 Project Topics:

- Create (or update, as applicable) a "complete and keyword optimized" LinkedIn profile as described in text

- Develop/build/expand their LinkedIn network

- Join certain LinkedIn groups

- Show evidence of relevant engagement in LinkedIn

- Promote a LinkedIn group

- Find relevant content to share with other connected LinkedIn members

- Market themselves - develop a You Tube video and attach a personal professional profile

In addition to information related to LinkedIn, the course instructor provides in-class lectures emphasizing the ways in which various other social media can be used as effective professional selling tools (e.g., Twitter, Facebook, Pinterest, Instagram, Google + Blogging). The instructor has the flexibility of selecting media and topics deemed appropriate due to the dynamic nature of the sales discipline and of social media. Some suggested topics for class discussion/lectures include:

- Generating leads with social media

- Attracting attention to your online presence

- Time management with social media

- How to communicate with prospects online

- How to leverage your social media, etc.

Throughout this module, the instructor is encouraged to invite social media experts/sales professionals with appropriate and relevant experience as guest speakers in the classroom. In the Capstone Sales course described here, a LinkedIn expert housed in the University's business school and another housed in the University's Career Services unit served in this role. Students are required to complete and submit written reaction/report pieces for each such guest speaker in this module. Each Guest Speaker report is worth up to 30 points ( 5 points for asking a question of the speaker and 25 points for the balance of the reaction paper). The instructor provides a Guest Speaker Reaction write-up guideline for the students (see Appendix A.)

During the last week of this $1^{\text {st }}$ module of the course, students take an exam designed to assess their knowledge of the course content covered during the 4 weeks of the module. Finally, the final class day of this module is devoted to class discussion regarding student experiences and learning. The following comments from students are illustrative of some such learning:

One of the LinkedIn connections I made, and who worked for Oracle at the time, even reached out to me in a phone call and gave me some great advice for finding a job and said if I ever wanted to get into the tech sales industry to let him know. - Daniel

By connecting via LinkedIn, I've been able to network with professionals through $2^{\text {nd }}$ and 3rd degree connections. I've had the opportunity to do informational interviews with marketers and to learn more about what their job entails and what career advice they have for me. -- Jasmine

\section{Module 1 Deliverables by the Instructor}

An important instructor deliverable in this $1^{\text {st }}$ course module is a thorough and clear introduction to the overall course and its modules, information on the project for the first module, social media related classroom content, management of project progress, the grading rubric for the LinkedIn project (see below), administration of the examination, and guidance of class discussion. This deliverable is key to student understanding of the course learning objectives and the pedagogy implemented in the course. 


\section{LinkedIn and Social Media Report Grading Rubric}

\begin{tabular}{|c|c|c|c|c|c|}
\hline Criteria & Excellent & Good & Satisfactory & $\begin{array}{l}\text { Needs } \\
\text { Improvement }\end{array}$ & $\begin{array}{ll}\text { Score and } \\
\text { Feedback }\end{array}$ \\
\hline $\begin{array}{l}\text { The Value of } \\
\text { Social Media }\end{array}$ & 50 points & 45 points & 40 points & 35 points & \\
\hline $\begin{array}{l}\text { LinkedIn } \\
\text { Photo } \\
\text { (professional) }\end{array}$ & 10 points & 9 points & 7 points & 6 points & \\
\hline $\begin{array}{l}\text { LinkedIn } \\
\text { Summary }\end{array}$ & 20 points & 18 points & 15 points & 12 points & \\
\hline $\begin{array}{l}\text { LinkedIn } \\
\text { Experience }\end{array}$ & 20 points & 18 points & 15 points & 12 points & \\
\hline $\begin{array}{l}\text { LinkedIn } \\
\text { Education }\end{array}$ & 10 points & 9 points & 7 points & 6 points & \\
\hline $\begin{array}{l}\text { LinkedIn } \\
\text { Following }\end{array}$ & 10 points & 9 points & 7 points & 6 points & \\
\hline $\begin{array}{l}\text { LinkedIn } \\
\text { Connections }\end{array}$ & 20 points & 18 points & 15 points & 12 points & \\
\hline Criterion 8 & 10 points & 9 points & 7 points & 6 points & \\
\hline Overall Score & $\begin{array}{l}\text { Level } 4 \\
31 \text { or more }\end{array}$ & $\begin{array}{l}\text { Level } 3 \\
23 \text { or more }\end{array}$ & $\begin{array}{l}\text { Level } 2 \\
15 \text { or more }\end{array}$ & $\begin{array}{l}\text { Level } 1 \\
0 \text { or more }\end{array}$ & \\
\hline
\end{tabular}

Module 1 Deliverables by the Student

During this module, students will complete and submit Guest Speaker Reaction pieces (see Appendix A). By the end of the $4^{\text {th }}$ week of the course, each student will complete and submit the assigned LinkedIn Project and complete the Module 1 Course Examination.

\section{Module 2: Professional Selling Practicum and Shadowing (4 weeks)}

Content: In this $2^{\text {nd }}$ module of the Capstone Sales course, each student is required to complete 2 primary assignments. Assignment 1 requires each student to identify one or more professional salespersons and to schedule a sales call shadowing/ride-along experience with those sales experts and to complete a written report detailing the shadowing experience and learning takeaways. As noted above, students begin initial work on these shadowing experiences in Module 1 of the course. For those students who find themselves unable to identify their own sales professionals for the shadowing activities, the instructor provides a list of salespeople who have volunteered to serve in the shadowing capacity. Instructors are urged to require that students experience a minimum of 2 field sales calls and a minimum of 2 inside (telephone/virtual) sales calls as part of the salesperson shadowing experience.

For this assignment, students are required to develop a target group of 5 firms selected from an instructor provided list of approved companies. This list is developed, in part, from firms belonging to area Chambers of Commerce, the Top 100 firms (both public and private) as listed on government provided websites, and from firms involved in the Herberger Business School's Professional Selling Specialization program. Students have the option to select one or more firms not included in the approved list but such selections require instructor approval. The instructor encourages students to select organizations which hold career interest for them. After completing the shadowing assignment(s), each student prepares a detailed report on the shadowing experience(s). Instructors have the flexibility to develop specific and timely requirements for the report. A detailed Salesperson Shadow Experience and Report Write-Up Guideline is presented in Appendix A.

A second Module 2 assignment requires students to participate in the computerized MARS (Marketing and Sales Management Simulation) game. The instructor introduces and provides an overview of the simulation and of associated student requirements. The class is divided into teams comprised of 4 or 5 students each and all teams 
compete one against the other on measures of overall profitability as related to product sales and are graded upon their final rankings in the simulation. Those rankings are based upon the teams' simulated management of a virtual sales force consisting of 5 sales representatives selling a line of computer games. Each virtual sales representative managed by the student teams is at a different stage of his/her sales career (in terms of experience, performance, etc.) All student teams supervise the same 5 sales representatives and each representative, with unique sales territories, is motivated differently.

There are 8 to 12 decisions in each simulation exercise and each exercise covers a 2 to 3 - year simulated time period. Each student team arrives at data driven decisions in each week of the module. Data for the simulation is entered by student groups by the last class day of each week. A timeline that suggests the number of simulation exercises is provided at the end of this proposal. The instructor serves as a guide/consultant during the simulation activities. Class session time is allocated for student teams to collaborate on, input, and discuss MARS decisions and decision outcomes.

The learning objective of the simulation is to have students actively learn about sales management - to "learn by doing' as they make weekly decisions regarding a number of sales management variables: compensation plans (salary, commission, bonus), quotas, training, supervision, sales representative time management for clients/accounts of varying sizes, sales representative recognition/awards and contests. The simulation demonstrates to the students how each of their decisions regarding these variables works in an integrated fashion to impact the performance of their sales force. The MARS also illustrates the effectiveness of different motivation strategies on diverse types of sales representatives.

It is suggested that the instructor consider inviting area sales professionals to participate in this module as guest lecturers on certain topics deemed appropriate by the instructor. Likely topics might include perspectives of the sales discipline and professional selling as a career, tactics and practices of successful sales people, the sales process of the sales person's organization, the relationship between the sales force and other organizational units/departments and more. As in Module 1, students submit written Guest Speaker Reaction papers for each such guest speaker.

The final day of class in this $2^{\text {nd }}$ module is devoted to class discussion regarding student experiences and learning outcomes. Below are some samples of student experiences shared during these discussion sessions:

I found the different selling techniques that were used with different customers to be surprising. The sales person tried to get the customer's level and to understand their issues and figure out the best way to solve those issues by providing a product that would be beneficial to the customer. - Bradley

Although Steve relies on technology and his iPad and brings one with him everywhere he goes, using apps to show him how each of his stores is performing and to score each store after his visit, he also has a lot of contact with his customers every day. When we walked through the stores, many people greeted him and had good relationships with him. - Hanna

Module 2 Deliverables by the Instructor

It is imperative that during this module of the course the instructor effectively and clearly organizes and manages the shadowing assignment and associated processes. Such organization and management activities include working closely with students to understand the logistics and the importance of shadowing experiences as well as motivating students to undertake the necessary shadowing activities in a timely manner. Experience has shown that students commonly lack confidence in their ability to take the first steps in the shadowing assignment and, if allowed, will convince themselves that they lack the connections and/or ability to identify and contact sales professionals. In this module the instructor also introduces, lectures on, and manages the MARS simulation, organizes and manages guest lectures, guides sales management case discussions and overall class discussion.

Module 2 Deliverables by the Student:

Students are required to complete and submit written Guest Speaker Reaction papers for each guest speaker presentation. By the end of the final week of this module, students are required to complete and submit their Shadowing Reports and to complete the MARS simulation activities.

\section{Module 3: Sales Management Practicum and Shadowing (4 weeks)}

Content: Students shadow a sales manager(s) for 2-4 hours over one or more days and observe the day-to-day activities and practices of those managers. The logistics of this experiential learning are determined in part by the number of sales managers identified for this assignment. For example, if adequate numbers of participating sales managers allow, students work as individuals on these shadowing assignments. If, on the other hand, limited number 
of sales managers have been identified, students might work in pairs on these experiences. The instructor also has the flexibility to require fewer or more shadowing hours depending upon his/her preferences, learning goals, and upon discussions with participating sales managers. Some desirable interactions students are exposed to during these shadowing experiences include:

- One-on-one meetings with sales managers

- Attendance of one or more group sales meetings with the sales manager and members of the sales force

- Product or sales training with the sales manager or appropriate designees

- Merchandising meeting with the sales managers and appropriate professionals

- One-on-one meetings with sales managers for debriefing of group sales meetings

By the final week of this module, each student submits a detailed written report of their sales management shadowing experience(s). The assignment includes interviews with the sales manager(s), student observations, and student evaluations of their experience(s). Students are provided with a Sales Manager Interview rubric (See Appendix A). In an effort to help students develop appropriate and firm-specific interview questions, the instructor strongly encourages students to research (via web sites, annual reports, etc.) firms of interest.

Students also continue the MARS games in this module. Upon completion of the simulation, usually in the $4^{\text {th }}$ and final week of the module, student teams submit a final MARS summary report in which they detail their strategies and learning takeaways. Below are some examples of student reactions to the simulation:

As in Modules 1 and 2, sales managers are invited to the classroom to provide guest lectures on topics deemed appropriate by the instructor. Suggested topics for guest lecturers include but are not limited to characteristics of successful sales people and the hiring perspectives, sales processes and day-to-day activities and duties of the sales manager(s) and their firms, interactions with sales force members in various settings, sales training programs, and motivational tools and practices. Again, students are required to submit Guest Speaker Reaction papers.

The final class day of this module is devoted to class discussion regarding students' shadowing experiences with sales managers and associated learning outcomes. Students are encouraged to share their perceptions of and takeaways from their sales manager shadows and from the MARS simulation. Some examples of such takeaways are provided below:

"Throughout the shadowing experience, I learned what it is like to be a part of a sales team. It was valuable to learn about a company's culture and talk not only to the sales manager but to other members of the team about their experience with the company and why they enjoy coming to work every day." - Addison

"There were 2 regional sales managers, a manager of store relations, two marketing coordinators and one product coordinator in the meeting. We went through their summer promotional plan, product by product. Topics of discussion included new product flavor, the displays for those products, client relations, consumer marketing, pricing and some salesperson training. The shadow really showed me just how much is involved with a 'big' brand like this."-Mike

The MARS simulation exposed us to a real-world experience with sales management decisions - Marlo

The uniqueness of the sales simulations made the class interesting and engaging - Leigh

Module 3 Deliverables by the Instructor:

In this the $3^{\text {rd }}$ module of the Capstone Sales course, the instructor continues to administer the MARS sales management simulation (running the simulation after student teams have entered their sales management decisions, providing student teams with outcome related conclusions, giving suggestions and guidance to groups as prompted/suggested by simulation results, etc.), and discusses various sales management issues as they relate to the MARS simulation. The instructor also helps the students develop and coordinate their sales manager shadowing contacts and engages student groups in classroom discussions of their shadowing experiences and insights.

Module 3 Deliverables by the Student:

Each student completes and submits his/her Guest Speaker Reaction reports as well as their Sales Manager Shadowing Reports. Student teams complete the MARS simulation and submit a written report detailing associated learning and takeaways. 


\section{Module 4: Global Marketing/Culture in Professional Selling (3-4 Weeks)}

Content: In this $4^{\text {th }}$ and final module of the Capstone Sales course, the instructor provides a variety of course lectures based upon his/her review of relevant and timely literature and associated works. (A suggested book for lecture content, "Kiss, Bow, or Shake Hands, Sales and Marketing: The Essential Cultural Guide - From Presentations and Promotions to Communications and Closing" by Terri Morrison and Wayne A. Conaway, 2011.) Likely lecture topics in this module are adopted from this book and include but are not limited to a global perspective on: Background and Culture, Tips on Doing Business, Protocol, Business Practices, Key Phrases, and more as each relates to the professional selling discipline.

During the final two weeks of this 3-4week module (depending upon how the instructor structures the course), student teams make formal classroom presentations based upon their research of the sales discipline in global settings. Each of these teams, comprised of 4-6 students, selects a specific region of the world and investigates the professional selling environment, strategies, methods, etc. in those regions. The teams make an oral presentation, including a Power Point or similar slideshow, detailing the results of their research. An alternative assignment might be to require students to submit a report outlining cultural and behavioral differences in buyer-seller dynamics across different regions or countries.

As in the previous modules of the course, sales managers are invited to guest lecture in this module and to focus on topics such as culture and its relationship to business, communication - both verbal and nonverbal - and its importance in international professional selling, adapting to culture and norms, industry trends, similarities and distinctions, and more. Students are required to submit Guest Speaker Reaction papers for each such guest lecturer.

The final class room session of this module consists of summary class discussion of student experiences and learning. Some examples of student takeaways from the Capstone Sales course indicate that students are indeed developing a deeper and more thorough understanding of the sales discipline:

I gained knowledge of the sales industry and the industry tours and guest speakers were valuable... and I got a job in professional selling! -- Ashlyn

Now I better understand that the best way to sell something is to go at it from the customer's point of view. This class has also helped me understand what it takes to be successful in a sales position - Brady

This class is not only about selling in the future - it helped me gain confidence in myself and how to sell myself. Alexa

Module 4 Deliverables by the Instructor:

In this module of the course, the instructor's responsibilities are primarily to raise the students' awareness and knowledge of the impact of global diversity on the professional selling discipline. Experience has shown that the inclusion of guest speakers in this course module, coupled with the students' research on sales practices in various countries, accomplishes both objectives. As such, in terms of student learning, a key to the success of this module hinges upon the instructor's ability to involve guest speakers in classroom discussions.

Module 4 Deliverables by the Student:

Student teams develop and present the findings of their research on professional selling in global settings and complete and submit their related written reports.

\section{Summary and Conclusions}

The primary objective in writing this paper was to provide an overview of the Capstone Sales course in a professional selling certificate program in an AACSB accredited university. In addition, our goal was to present course details - including instructor and student deliverables, suggested timelines, activity grading and writing rubrics, and more - at a level which would help interested instructors at other institutions develop and implement a similar course. Those course details are intended as broad, flexible guidelines that can be readily changed and adapted to fit the needs and preferences of other instructors and programs. As an example of one such change, after two semesters the MARS game was removed from the Capstone Sales course and implemented in the Marketing Department's Sales Management course.

It is important to note that, much like the professional selling and marketing disciplines, environmental influences and changing business needs will over time necessitate changes in the Capstone Sales course presented in this paper. For example, our disciplines have recently experienced significant changes in the application of social media and technology at virtually all levels of need based selling. As future growth in the school's sales program is 
contemplated, the sales faculty envisions a ramping up of course activities focusing on social media, mobile and internet selling, customer relationship management, and so on. A key to such changes will be ongoing discussions with sales professionals across the region, the nation and even the globe.

\section{References}

Alvarez, C.M.O., Taylor, K.A., \& Rauseo, N.A. (2015). Creating Thoughtful Sales People: Experiential Learning to Improve Critical Thinking Skills in Traditional and Online Sales Education. Marketing Education Review, 25(3), Fall, 233-243. https://doi.org/10.1080/10528008.2015.1044859

Angihotri, R. Kothandaraman, P., Kashyap, R. \& Singh, R. (2015). Bringing 'Social' Into Sales: The Impact of Salespeople's Social Media Use on Service Behaviors and Value Creation. Journal of Personal Selling and Sales Management, 32(3), Summer, 333-348.

Canaday, Henry. (2012). A Socially Salable World. Selling Power Magazine. April/May/June, pp. 46-50.

Chapman, J., Schetzsle, S. \& Wahlers, R. (2016). An Innovative, Experiential-Learning Project for Sales Management and Professional Selling Students. Marketing Education Review, 26(1), 45-50. https://doi.org/10.1080/10528008.2015.1091674

Cummins, S., Peltier, J. W., Erffmeyer, R., \& Whalen, J. (2013). A Critical Review of the Literature for Sales Educators. Journal of Marketing Education, 34(1), 68-78. https://doi.org/10.1177/0273475313481157

Featherstonebaugh, B. (2010). The Future of Selling: It's Social. Forbes.com, December 3. www.forbes.com/2010/12/03/future-of-selling-leadership-sales-leadership-ogilbyone.html

Fuhr, Scott. (2012). Good Hiring Makes Good Cents. Selling Power Magazine, July/August/September, 20-21.

Hawes, J.M., \& Foley, L.M. (2006). "Building Skills With Professional Activity Reports." Marketing Education Review, 16(1), Spring, 35-40. https://doi.org/10.1080/10528008.2006.11488935

Moore, J.N., Raymond, M.A., \& Hopkins, C.D. (2015). Social Selling: A Comparison of social Media Usage Across Process Stage, Markets and Sales Job Functions. Journal of Marketing Theory and Practice, 23(1) Winter, 1-20. https://doi.org/10.1080/10696679.2015.980163

"Why Great Sales People are Always in Demand". (2017). Humres Technical Recruitment Ltd. http://www.humres.co.uk/

Selling Power Magazine.

(2016).

http://www.sellingpower.com/content/article/index.php?a=10545/selling-power-500/largest-sales-forces/2016 


\section{Appendix A.}

\section{Suggested Timeline of Activities and Tasks for a 16 Week Semester}

Week 1: Introduction to Course, Module Requirements, Projects for Module 2, 3, and 4, LinkedIn project

Week 2: (Module1): Class Lectures/Time to work on LinkedIn project

Week 3: (Module1): Class Lectures/Guest Lecture

Week 4: (Module1): Class Lecture, LinkedIn project question and answer session

Week 5: (Module1): Exam, Project due, Class discussion of Module 1 experience and learning

Week 6: (Module 2): Introduction to MARS simulation, in-class time to work on Mars simulation

Week 7: (Module 2): MARS output provided; Time for salesperson shadowing

Week 8: (Module 2): Guest salesperson(s) lecture, student teams work on MARS simulation

Week 9: (Module 2): Student teams work on MARS simulation (in class); Sales person shadowing report due; Class discussion on shadowing experience and learning

Week 10: (Module 3): Student teams work on MARS simulation (in class)

Week 11: (Module 3): MARS output and question and answer session (in class), Sales Manager Shadowing

Week 12: (Module 3): Guest Sales Manager, student teams work on MARS simulation (in class)

Week 13: (Module 3): MARS decision/outcome discussion; Shadowing Report; Shadowing experience discussion

Week 14: (Module 4): Class lectures

Week 15: (Module 4): Class lectures

Week 16: (Module 4): Student Presentations

Exam Day: Discussion on Module 4, Discussion/feedback on entire course

NOTE: This is a general timeline, the instructor should evaluate module requirements carefully while developing class session schedules

\section{Guest Speaker/Lecturer Reaction Paper Guidelines}

(Your paper should be word processed and in outline format)

1. Title Block

2. Reviewed company's Web site prior to visit:

3. Ask guest speaker at least one informed question: (5 points) You better be the first to ask your question; not everyone will get these points due to time constraints)

a. What question did you ask?

4. Questions related to the guest lecture/presentation:

a. What were the Top 5 issues presented and which were of interest to you? (10 points)

b. What impressed or surprised you about the discussion/presentation issues? (10 points)

c. What did you learn from the guest speaker? (5 points) 


\section{Salesperson/Sales Manager Shadow Experience and Report Write-Up Guidelines}

1) Select and submit a Target List of five companies from approved company list. If desired company not on list, approval must be given from instructor. TRY TO SELECT COMPANIES IN WHICH YOU HAVE CAREER INTEREST. (Reference course syllabus for due date).

a) Approved Company List (students are provided with links to appropriate web links)

b) Find information on the Web and document sources.

c) Obtain relevant information from company (Web site(s); Annual Reports

2) Salesperson Shadow Write-Up's (Reference Syllabus for due date)

a) Title Block

b) Salesperson Contact Information:

Name:

Company:

Company Address:

Company Phone:

Salesperson's Cell Phone:

Salesperson's E-mail:

c) Appointment scheduled date and time:

d) Appointment made prior to due date (20 points):

e) Appropriate attire was worn by student to appointment (asked salesperson):

f) Arrived at appointment on time scheduled (early is OK and wait):

g) Amount of time spent with Salesperson:

h) Activities engaged in with Salesperson (20 points):

i) Made outside field sales calls

ii) Made inside sales calls (customer(s) came to Salesperson's Company)

iii) Made inside phone sales calls

iv) Other

3) What did you observe about the Salespersons sales process used: ?

4) Did the Salesperson close a sale while you were together? If yes, explain:

5) Observations (20 points):

a) What were the Top 5 issues discussed with the Salesperson:

b) What surprised you about the discussion or the situation:

c) If you could have done something different in this situation, what would it have been:

d) Overall, what was your observation on how this Salesperson handled the situation and or conversation with you or clients:

e) What did you learn from this "Salesperson Shadow Experience:"

6) Thank you e-mail or letter sent to Salesperson (20 points)

7) Student Evaluation given to Salesperson and received by Professor (20 points)

NOTE: These guidelines are adapted for application to the Sales Manager Shadowing Experience 